\title{
Outcome of Vesicovaginal Fistula Repair at Urology Department STH Swat
}

\author{
Nizamuddin', Fazal Elahi', Mumtaz Ali ${ }^{2}$, Fazli Akbar ${ }^{3}$, Mohammad Hussain $^{3}$, Shumaila Gul ${ }^{4}$
}

\begin{abstract}
Background: Vesicovaginal fistula is an abnormal passage between the bladder and the vagina, which leads to continuous , involuntary loss of urine through the vagina.It is the most usual type of acquired genitourinary fistulas.

Objective: To determine outcomes of vesicovaginal fistula repair at Urology Department, Saidu Teaching Hospital, Swat.

Material and Methods: This descriptive study was conducted in Department of Urology, Saidu Group of Teaching Hospitals, Swat from September, 2016 to February, 2019. Patients with age group of 25-65 years, diagnosed with VVF were repaired either through abdominal or vaginal route. These patients were prospectively analysed and the demographic profile, route of surgery and outcomes were noted down.

Results: A total of 58 patients were included in the study. The causes were obstructed labour in 26 patients, post-operative trans abdominal hysterectomy and caesarean section in 24 and 6 cases respectively. There was $100 \%$ success rate in abdominal repairs as compared to combined approach. Among the post-operative complications, bladder storage dysfunction was on the top, followed by urinary tract infections and wound infections.

Conclusion: The most common cause of VVF was prolonged obstructed labour. Overall, the success rate was $96.5 \%$. Irritative lower urinary tract symptoms were most commonly observed post operatively.

Key Words: Vesicovaginal fistula, outcomes, repair, complications.
\end{abstract}

This article may be cited as: Nizamuddin, Elahi F, Ali M, Akbar F, Hussain M, Gul S.

Outcome of Vesicovaginal Fistula Repair at Urology Department STH Swat. J Saidu Med Coll Swat 2020;10(2): 132-134

\section{INTRODUCTION}

Vesicovaginal fistula is an abnormal passage between the bladder and the vagina, which leads to continuous, involuntary loss of urine through the vagina. ${ }^{1}$ It is the most usual type of acquired genitourinary fistulas. ${ }^{2}$ Though it has become rare in the developed world but still it commonly occurs in the low resourced countries. It has been estimated that approximately three million women have untreated vvfs in the developing countries. ${ }^{4}$ Neglected obstructed labour is the major cause of vvf in the under developed world, which results in pressure necrosis which develops as a result of compression of the bladder between the symphisis pubis and impacted fetal head. Hence any instrumentation to this ischemic area can lead to fistula formation. ${ }^{5,6}$ Conversely, in the industrialised countries, the most common aetiology is iatrogenic injury, about $60 \%$ of which occurs during hysterectomies. ${ }^{7}$

Small size fistulas $=0.5 \mathrm{~cm}$, which present as single ,non radiated fistulas are termed as simple while recurrent or large sized fistulas $=2.5 \mathrm{~cm}$ are

1. Urology Unit, Saidu Group of Teaching Hospitals, Swat.

2. Nawaz Sharif Kidney Hospital, Swat

3. Surgery Unit, Saidu Group of Teaching Hospitals, Swat.

4. Post Graduate Resident, Surgery \& Allied, Saidu Group of Teaching Hospitals Swat.

Correspondence: Dr. Fazal Elahi, Senior Registrar Urology Unit, Saidu Group of Teaching Hospitals, Swat.

Email: dr.fazalelahi3@gmail.com

Cell: 03469405622 complex ones. Intermediate sized fistulas 0.5 - 2.5 $\mathrm{cm}$ are also considered as complex fistulas mostly.

The surgical technique, either tranabdominal (transperitoneal, extra peritoneal), transvaginal, laparoscopic or robotic, ${ }^{9,10,11}$ depends upon the expertise, the characteristics of patients and the type of fistula whether it's simple or complex. Simple fistulas can be easily approached vaginally by simple devascularised tissue excision and approximation of the remaining healthy tissues in multiple layers while complex or high fistulas are better approached abdominally. ${ }^{12}$ It is important to strictly follow the basic surgical principles defined by Couvelaire in 1953, "good visualization, good dissection, good approximation of the margins and good urine drainage, to maximise the chances of successful vvf repairs. $^{13}$

\section{MATERIALAND METHODS}

This is a descriptive, prospective study conducted at Urology Department, saidu group of Teaching Hospitals Swat, from September 21, 2016 to February 21, 2019. During the study period, all the patients coming with continuous leakage of urine per vagina and diagnosed on the basis of history, clinical examination and investigations (cystogram and cystoscopy) as vesico vaginal fistula were included. Patients with failed previous repair were also included in the study. The total number of patients was fifty eight (58) with age group ranging between 25-65 years. Informed consent was taken from the patients. After pre 
operative work-up, fistula repair was done either through abdominal or vaginal route in two layers tension free and water tight with absorbable suture, which was decided by the type, size, number and site of the fistula. The patients were kept on antibiotics in the early post operative period and then discharged with indwelling catheter for two weeks. They were called for follow up visits at two weeks initially and then depending on the presence of symptoms later on. These patients were prospectively analysed for two and half years and the data regarding demographic profile of the patients included in the study, nature of fistula, route of surgery and outcomes of repair were noted. Data was collected on preformed designed proforma with informed consent and was analysed on by using SPSS20.

\section{RESULTS}

A total of $58 \mathrm{vvf}$ repairs were performed over the study period of two and half years. The age range of the patients was 25- 65 years. The causes of vvf in these patients were obstructed labour in 26 cases, followed by post operative trans abdominal hysterectomy (TAH) in 24 patients, post operative caesarean section in 6 and fire arm injury in a 2 cases (see fig.1). Among them 22 were re-do cases with history of failed previous repair, 6 cases were having ureteric involvement among the re-do cases and 4 patients had multiple fistulae among the 36 fresh ones. These repairs were carried out trans-abdominally in 56 patients and via combined approach (trans abdominal \& trans vaginal). 2 patients who had multiple fistulae high fistula which was above trigone were repaired transabdominally and low fistula which was lying below trigone was repaired transvaginally. All the cases approached through abdominal route were successful while those with both trans abdominal and trans vaginal approach were failed. Overall, the success rate was $96.5 \%$ (see fig.2).

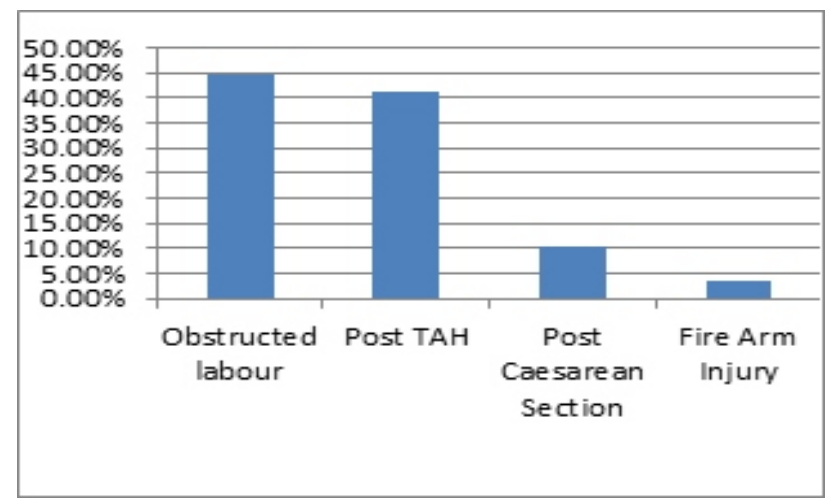

Fig.1 Aetiology of VVF.
$26(44.8 \%)$ patients developed storage dysfunction post operatively, which was successfully managed with anti-cholinergics. 20 $(34 \%)$ patients were noted with urinary tract infections and $2(0.03 \%)$ with wound infection (see fig.3).

\begin{tabular}{|lll|}
\hline $\begin{array}{l}\text { Route of VVF } \\
\text { repair }\end{array}$ & $\begin{array}{l}\text { No. of } \\
\text { patients }\end{array}$ & $\begin{array}{l}\text { Success } \\
\text { rate \% }\end{array}$ \\
\hline $\begin{array}{l}\text { Trans-abdominal } \\
\begin{array}{l}\text { Combined ( trans- } \\
\text { abdominal \& tran- } \\
\text { vaginal) }\end{array}\end{array}$ & 56 & $100 \%$ \\
\hline Grand Total & 58 & $96.5 \%$ \\
\hline
\end{tabular}

Fig. 2 Success Rate of VVF repair.

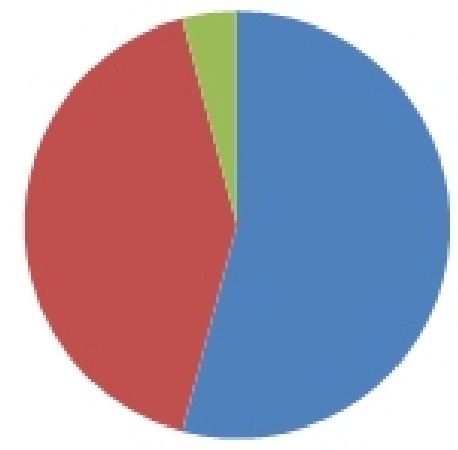

nStorage

dysunction:

$44.8 \%$ (26 pts.)

-Urinary tract

infections: $34 \%$

(20 pts.)

-Wound infection:

$0.03 \%$ (2 pts.)

Fig. 3 Complications of VVF repair.

\section{DISCUSSION}

This study revealed that prolonged obstructed labour was the leading cause of vesico vaginal fistula similar to the results in a study conducted by Wall et al. ${ }^{14}$ It was estimated in a study done in West Africa that vvf occurred in 1-3 per 1000 deliveries. ${ }^{15}$ This is most probably due to the lack of modern obstetric care and practice of early marriages where mothers experience labour before reaching full maturity. On the contrary, many studies showed gynaecologic surgeries, mostly hysterectomies, to be on the top for causing vvf. ${ }^{16,17,18,19}$ The factors affecting success rate of surgical repair of vesico vaginal fistula are radiation, ischemia of the tissue and previously failed repair. ${ }^{20}$ None of the patients included in the study had previous history of pelvic irradiation, yet $38 \%$ of them were recurrent cases.

Studies conducted by Ockim, et al. reported $75 \%$ success rate in abdominal VVF repairs and $94 \%$ 
success noted by Hadzi-Djokic. ${ }^{21,22}$ While our study unveiled that all the patients with vesico vaginal fistulas repaired through abdominal approach were successful. These results were found consistant with study conducted by Rahjamaheswari. ${ }^{23}$ In contrast, it was reported that abdominal fistula repair without omental flap interposition had high failure rates. ${ }^{24}$ Our analysis clearly declared that surgical approach affected the outcome of surgery. Combined (trans abdominal and trans vaginal) approach was associated with higher failure rates as compared to abdominal route.

This study made it certain that $45 \%$ patients developed lower urinary tract symptoms post operatively as compared to study conducted by Dolan et al. which reported $87 \%$ patients having urinary symptoms. ${ }^{25}$ The storage dysfunctions of the bladder can affect healing and be a discomfort for patients, which can be effectively managed with anticholinergics. ${ }^{26}$

\section{CONCLUSION}

This study showed that accurate and quick diagnosis is essential for timely repair which can reduce the distress caused by VVF and improve the outcomes. It is important to strictly follow the basic surgical principles to accomplish a successful VVF repair.

This study showed that obstructed labour was on the upward trend for causing VVF. Abdominal vvf repair had increased success rates as compared to vaginal repair, both done without intervening layer. Post operative complications like bladder dysfunctions, urinary tract infections and wound infections were managed successfully.

\section{REFERENCES}

1. Bodner-Adler B, Hanzal E, Pablik E, Koelbl H, Bodner K. Management of vesicovaginal fistulas (VVFs) in women following benign gynaecologic surgery: A systematic review and meta-analysis. PLoS One. 2017; 12(2): e0171554.

2. Greenlee RT, Murray T, Bolden S, Wingo PA. Cancer statistics, 2000. CA Cancer J Clin 2000;50:7-33.

3. Waaldijk K. Surgical classification of obstetric fistulas. Int J Gynecol Obstet. 1995;49:161-163. doi: 10.1016/0020-7292(95)02350-L

4. Wall LL. Obstetric vesicovaginal fistula as an international public-health problem. Lancet 2006; 368: 1201-09.

5. Tahzib F. Epidemiological determinants of vesicovaginal fistulas. $\mathrm{Br} J$ Obstet Gynaecol. 1983;90:387-391. doi: 10.1111/j.14710528.1983.tb08933.x.

6. Hillary CJ, Chapple CR. The choice of surgical approach in the treatment of vesico-vaginal fistulae. Asian J Urol. 2018 Jul;5(3):155-9.
7. Hillary CJ, Osman NI, Hilton P, Chapple CR. The aetiology, treatment, and outcome of urogenital fistulae managed in well- and low-resourced countries: a systematic review. Eur Urol. 2016;70:478-92

8. Stamatakos M, Sargedi C, Stasinou T,_Kontzoglou K. Vesicovaginal Fistula: Diagnosis and Management. Indian J Surg. 2014 Apr; 76(2): 131-36.

9. Iselin CE, Alsan P, Webster GD. Transvaginal repair of vesicovaginal fistulas after hysterectomy by vaginal cuff excision. J Urol. 1998; 160: 728-30.

10. Raz S, Bregg KJ, Nitti VW, Sussman E. Transvaginal repair of vesicovaginal fistula using a peritoneal flap. J urol. 1993; 150: 56-59.

11. Bazi T. Spontaneous closure of vesicovaginal fistula after bladder drainage alone: review of the evidence. Int Urogynecol J pelvic Floor Dysfunct. 2007; 18(4): 475-481.

12. Tatar B, Oksay T, Selcen Cebe F, Soyupek S, Erdemoğlu $\mathrm{E}$. Management of vesicovaginal fistulas after gynecologic surgery. Turk J Obstet Gynecol. 2017 Mar; 14(1): 45-51.

13. Couvelaire R. Reflections on a personal statistics of 136 vesicovaginal fistulas. J Urol Medicale Chir 1953;59:150-60.

14. Wall LL, Karshima JA, Kirschner C, Arrowsmith SD. The obstetric vesicovaginal fistula. characteristics of 899 patients from Jos Nigeria Am J Obstet Gynecol, 2004;190: 1011-19.

15. Elkins TE. Surgery for the obstetric vesicovaginal fistula: A review of 100 operations in 82 patients. Am J Obstet Gynecol 1994;170:1108-18

16. Tancer ML. Observations on prevention and management of vesicovaginal fistula after total hysterectomy. Surg Gynecol Obstet 1992;175:501-6.

17. Goodwin WE, Scardino PT. Vesicovaginal and ureterovaginal fistulas: A summary of 25 years of experience. J Urol 1980;123:370-4.

18. Kochakarn W, Pummangura W. A new dimension in vesicovaginal fistula management: an 8-year experience at Ramathibodi hospital. Asian J Surg. 2007;30:267-71.

19. Blaivas JG, Heritz DM, Romanzi LJ. Early versus late repair of vesicovaginal fistulas: vaginal and abdominal approaches. J Urol. 1995 Apr;153(4):1110-2; discussion 1112-3.

20. C. Chapple R. Turner-WarwickVesico-vaginal fistula BJU Int, 2005;95:193-214.

21. Ockrim JL, Greenwell TJ, Foley CL, Wood DN, Shah PJ, Atertiary experience of vesico-vaginal and urethrovaginal fistula repair: factors predicting success. BJU Int 2009;103: 1122-1126.

22. Hadzi-Djokic J, Pejcic TP, Acimovic M. Vesico-vaginal fistula: report of 220 cases. Int Urol Nephrol 41: 299302.

23. Rajamaheswari N, Bharti A, Seethalakshmi K. Vaginal repair of supratrigonal vesicovaginal fistulae-a 10-year review. Int Urogynecol J 2019;23:1675-78.

24. Lee D, Dillon BE, Lemack GE, Zimmern PE Long-term functional outcomes following nonradiated vesicovaginal repair. J Urol 2014. 191: 120-124..

25. Dolan LM, Dixon WE, Hilton P. Urinary symptoms and quality of life in women following urogenital fistula repair: a long-term follow-up study. BJOG 2008; 115: 1570-74.

26. Carr LK, Webster G. Abdominal repair of vesicovaginal fistula. Urology. 1996;48(1):10-11. 